\title{
National Ignition Facility System Design Requirements \\ Laser System SDR002
}

D. W. Larson, J. M. Bowers, E. S. Bliss, V. P. Karpenko, and E. English

August 20, 1996

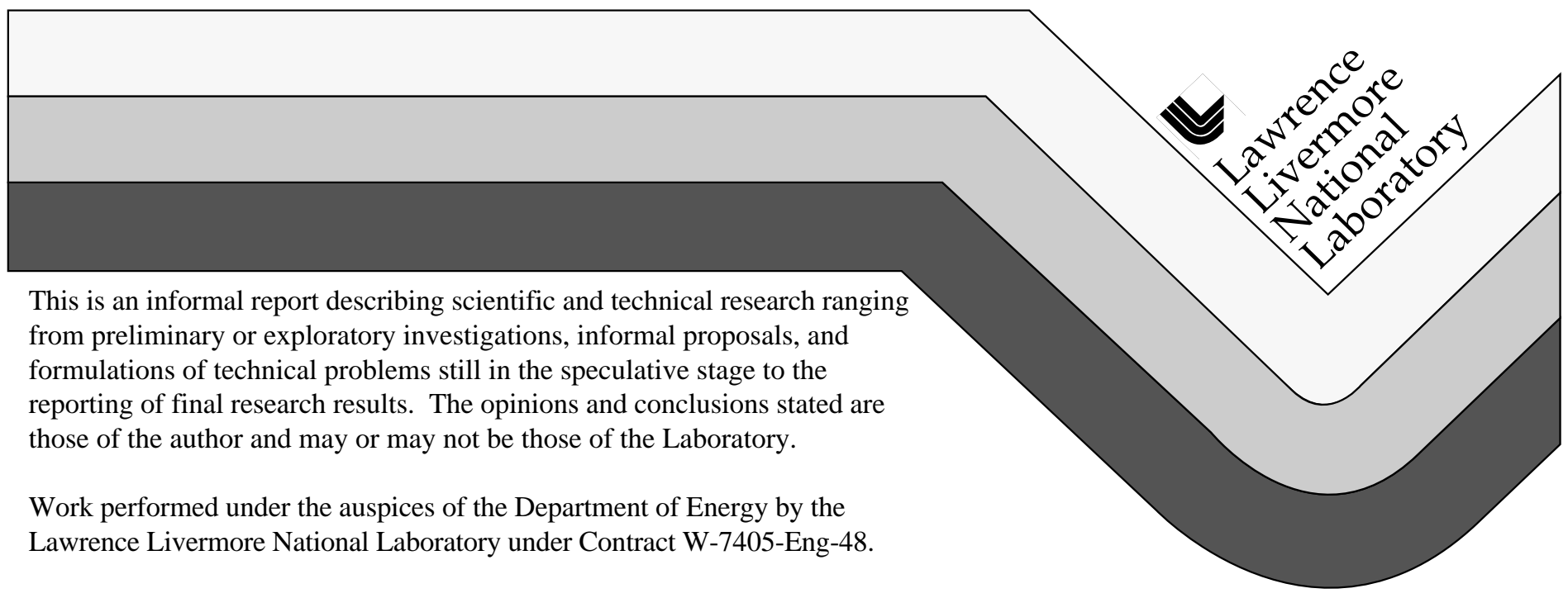




\section{DISCLAIMER}

This document was prepared as an account of work sponsored by an agency of the United States Government. Neither the United States Government nor the University of California nor any of their employees, makes any warranty, express or implied, or assumes any legal liability or responsibility for the accuracy, completeness, or usefulness of any information, apparatus, product, or process disclosed, or represents that its use would not infringe privately owned rights. Reference herein to any specific commercial product, process, or service by trade name, trademark, manufacturer, or otherwise, does not necessarily constitute or imply its endorsement, recommendation, or favoring by the United States Government or the University of California. The views and opinions of authors expressed herein do not necessarily state or reflect those of the United States Government or the University of California, and shall not be used for advertising or product endorsement purposes.

This report has been reproduced directly from the best available copy.

Available to DOE and DOE contractors from the Office of Scientific and Technical Information

P.O. Box 62, Oak Ridge, TN 37831

Prices available from (615) 576-8401, FTS 626-8401

Available to the public from the

National Technical Information Service

U.S. Department of Commerce

5285 Port Royal Rd.,

Springfield, VA 22161 
NIF-0000192-2

WBS 1.3

\section{National Ignition Facility}

\section{System Design Requirements \\ Laser System \\ SDR002}

\section{Revision 2}

August 20, 1996

Prepared by:

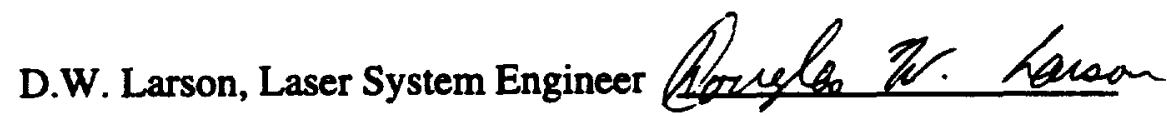

J.M. Bowers, Beam Transport System Engineer

Date

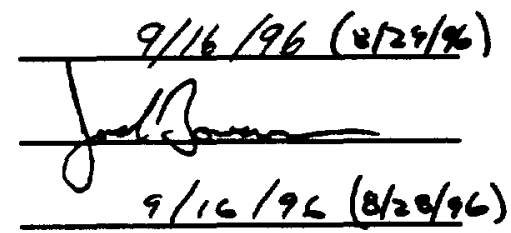

E.S. Bliss, System Controls System Engineer

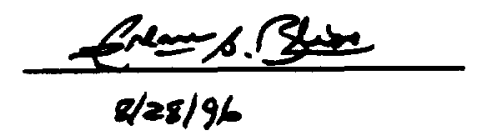

Date

V.P. Karpenko, Target Experimental System Engineer
E. English, Optical Integration Engineer Manager
Date
Date $9 / 16 / 96(8 / 20 / 96)$

Engineering Review Board Approval:

S. Kumpan, NIF Project Engineer

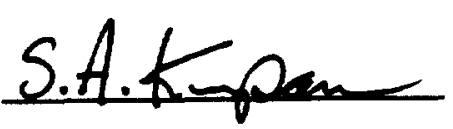

Approval Date

$$
9 / 6 / 96
$$

Level 3 Change Control Board Approval:

J. Paisner, NIF Laboratory Project Manager

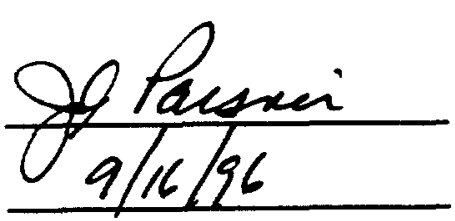




\section{Table of Contents}

\section{Paragraph}

1.0

2.0

2.1

2.1.1

2.1.2

2.1.3

2.1.4

2.2

2.2.1

2.2 .2

2.3

2.4

3.1

3.1.1

3.1.2

3.1.3

3.1.3.1

3.1.4

3.1.5

3.1.5.01

3.1.5.02

3.1.5.03

3.1.5.04

3.1.5.05

3.1.5.06

3.1.5.07

3.1.5.08

3.1.5.09

3.1.5.10

3.1.5.11

3.1.5.12

3.1.5.13

3.2

3.2.1

3.2.1.01

3.2.1.01.1

3.2.1.01.2

3.2.1.01.3

3.2.1.02

3.2.1.03

3.2.1.04

3.2.1.05

3.2.1.06

3.2.1.07
Title

Scope

Applicable Documents

Applicable NIF Documents

Applicable NIF Project Documents

Applicable NIF Drawings

Interface Control Documents

Subsystem Design Requirements Documents

Applicable US Government Orders and Standards

DOE Orders

Other Government Regulations

Applicable National Consensus Codes and Standards

Applicable LLNL Standards

System Definition

System Description

System Functions

System Diagrams

System Operating Modes

Primary Interfaces

Major Subsystems

Optical Pulse Generation System WBS 1.3.1

Amplifier System WBS 1.3.2

Pockels Cell System WBS 1.3.3

Amplifier Power Conditioning System WBS 1.3.4

Laser Auxiliary Systems WBS 1.3.5

Beam Transport Enclosures WBS 1.4.1

Interstage Subsystems WBS 1.4.2

Support Structures WBS 1.4.3

Beam Transport Optomechanical Systems WBS 1.4.4

Alignment Systems WBS 1.7.1

Beam Diagnostics WBS 1.7.2

Wavefront Control System WBS 1.7.3

Final Optics Assemblies WBS 1.8.7

Requirements and Verification

Performance Characteristics

Laser Energy and Power

Routine Operating Energy and Power

Maximum Design Energy and Power

Operating Energy and Power Envelope

Laser Pulse Wavelength

$1 \omega$ Wavelengths

Power Balance

Beam Positioning Accuracy and Stability

Laser Pulse Duration

Laser Pulse Dynamic Range 


\section{Table of Contents}

\section{Paragraph}

3.2.1.08

3.2 .1 .09

3.2.1.10

3.2.1.11

3.2.1.12

3.2 .1 .13

3.2.1.14

3.2 .1 .15

3.2.1.15.1

3.2 .1 .15 .2

3.2.1.15.3

3.2.1.15.4

3.2.1.16

3.2.1.17

3.2.1.18

3.2.1.19

3.2.1.20

3.2.1.21

3.2.1.22

3.2.1.22.1

3.2.1.22.2

3.2.1.22.2.1

3.2.1.22.2.2

3.2.1.22.2.3

3.2 .1 .23

3.2 .2

3.2.2.1

3.2.2.1.1

3.2.2.1.2

3.2.2.2

3.2.2.2.1

3.2.2.2.2

3.2.2.2.3

3.2.2.2.4

3.2 .3

3.2.3.1

3.2.3.2

3.2.3.3

3.2.3.4

3.2.3.5

3.2.3.6

3.2.4

3.2.4.1

3.2.4.2

3.2.4.3

\section{Title}

Capsule Irradiation Symmetry

Pre-pulse Power

Laser Pulse Spot Size

Beam Smoothness

Annual Number of Shots with Fusion Yield

Shot Turn-Around Time

Diagnostic Instrument Capabilities to Verify Laser Performance

Laser Firing Flexibility

Bundle Firing Flexibility

Beam Firing Flexibility

Beam Pulse Shape Flexibility

Laser Bay Operating Flexibility

Beam Focusing and Pointing Flexibility

Management of Unconverted ( $1 \omega$ and $2 \omega$ ) Light

Optical Clear Aperture

Number of Beams

SRRS Suppression

Low-Power and Low-Energy Laser Pulses

Experiment Compatibility

Classification Level of Experiments

Future Upgrades for Other Users

Future Additional Target Chamber

Radiation Effects Testing Capability

Other User Needs

Laser System Grounding System

Physical Characteristics

General Arrangement

Laser System Architecture

General Arrangement Drawings

Laser System General Configuration

Laser Bundles

Laser Quads

Laser Clusters

Laser Bays

Reliability, Availability, Maintainability

Lifetime

Replaceability

Inherent Availability

Reliability

Maintainability

Recovery from Abnormal Events

Environmental

Operating Ambient Temperature/Humidity

Ambient Cleanliness

Ambient Random Vibration Environment 


\section{Table of Contents}

\section{Paragraph}

\subsubsection{4}

3.3

3.3.01

3.3.01.02

3.3.02

3.3.03

3.3.03.1

3.3.03.2

3.3.03.3

3.3.03.4

3.3.03.5

3.3.04

3.3.04.1

3.3.04.2

3.3.05

3.3.05.1

3.3.05.2

3.3.06

3.3.07

3.3.08

3.3.11

3.3.12

3.3.13

3.3.14

3.3.14.1

3.3.15

3.3 .16

3.4

3.4 .1

3.4 .2

3.4 .3

3.6

3.6 .01

3.6.02

3.6 .03

3.6.04

3.6 .05

3.6 .06

3.6.07

3.6 .08

3.6 .09

3.6.10

3.6.11

\section{Title}

Back-Reflected Light

Design and Construction

Hazard Classification

Natural Hazards Classification

Radiation Protection

Safety

Life Safety

Laser Safety

Occupational Safety

Fail-Safe Design

Fire Protection

Cleanliness

Internal Optical Cleanliness

General Cleanliness

Environmental Protection Requirements

Waste Management

Effluents

Safeguards and Security

Future Modifications and Upgrades

Decontamination and Decommissioning

Human Factors

Interchangeability

Documentation and Records

Electrical Power

Voltage Quality

Design Processes

Supervisory Software Access to Distributed Control Points

Logistics

Spare Equipment

Maintenance Equipment

Bottom-Access Maintenance

Major Subsystem Characteristics and Verification

Optical Pulse Generation Characteristics and Verification (WBS 1.3.1)

Amplifier Subsystem Characteristics and Verification (WBS 1.3.2)

Pockels Cell System Characteristics and Verification (WBS 1.3.3)

Amplifier Power Conditioning System Characteristics and Verification (WBS 1.3.4)

Laser Auxiliary Systems Characteristics and Verification (WBS 1.3.5)

Beam Transport Enclosures Characteristics and Verification (WBS 1.4.1)

Interstage SubSystems Characteristics and Verification (WBS 1.4.2)

Support Structures Characteristics and Verification (WBS 1.4.3)

Optomechanical Systems Characteristics and Verification (WBS 1.4.4)

Alignment Systems Characteristics and Verification (WBS 1.7.1)

Beam Diagnostics Characteristics and Verification (WBS 1.7.2) 


\section{Table of Contents}

\section{Paragraph}

3.6 .12

3.6 .13

4.0

5.0

6.0

\section{Title}

Wavefront Control System Characteristics and Verification (WBS 1.7.3)

Final Optics Characteristics and Verification Characteristics and Verification (WBS 1.8.7)

QA Provisions

Notes

Revision Record 


\subsection{Scope}

This System Design Requirement document establishes the performance, design, development, and test requirements for the NIF Laser System. The Laser System generates and delivers high-power optical pulses to the target chamber, and is composed of all optical pulse creating and transport elements from Pulse Generation through Final Optics as well as the special equipment that supports, energizes and controls them. The Laser System consists of the following WBS elements:
1.3 Laser System
1.4 Beam Transport System
1.6 Optical Components
1.7 Laser Control
1.8.7 Final Optics

\subsection{Applicable Documents}

This section lists DOE orders, codes, and standards which are applicable to the NIF Laser System. The applicable portions of these documents apply. Applicable LLNL standards are considered contingent upon the decision of final site selection.

\subsection{Applicable NIF Documents}

The following NIF Project Documents apply to the Laser System as specifically referenced in later sections.

\subsubsection{Applicable NIF Project Documents}

National Ignition Facility Functional Requirements and Primary Criteria, Revision 1.4,L-15983-3, February, 1996.

"Proposed Metrication Policy for NIF," memo from R. Sawicki, NIF-LLNL-96-038, L-2124801,21 January, 1996

NIF Grounding Plan, NIF-LLNL-94-211, L-17346-1.

NIF-LLNL-93-044/L-15958-1, National Ignition Facility Quality Assurance Program Plan, November 1993.

\subsubsection{Applicable NIF Drawings}

The following NIF Project drawings apply as specified in sections 3.2 to 3.6. The specified revision applies. AAA-96-104900-0B, Final Optics Assembly AAA-96-104905-0A, Layout, Beam Transport Configuration AAA-96-100596-0B, LTAB NIF Optics Main Laser Optic System, 7/19/96 Parsons Drawing No CFG-201, "LTAB, Floor Plan at Level -0"', 4/16/96

\subsubsection{Interface Control Documents}

Interface requirements between WBS level 3 subsystems are controlled through separate Interface Control Documents (ICDs). See the document control system for the complete listing, and the most recent revision of each of these documents. 


\subsubsection{Subsystem Design Requirements Documents}

The following Subsystem Design Requirements Documents (SSDRs) specify design requirements for the major subsystems controlled by this SDR. See the document control system for the most recent revision of each of these documents.

SSDR1.3.1 Optical Pulse Generation System

SSDR 1.3.2 Amplifier System

SSDR 1.3.3 Pockels Cell System

SSDR 1.3.4 Amplifier Power Conditioning System

SSDR 1.3.5 Laser Auxiliary Systems

SSDR 1.4.1 Beam Enclosures

SSDR 1.4.4 Optomechanical Systems

SSDR1.6 Optical Components

SSDR1.7 Beam Control \& Diagnostic Systems

SSDR 1.8.7 Final Optics Assemblies

\subsection{Applicable US Government Orders and Standards}

\subsubsection{DOE Orders}

The following DOE orders are applicable to the Laser System.

- 5400.1 - General Environmental Protection Program

- 5480.1B - Environmental Protection, Safety, and Health Protection Program for DOE Operations

- 5480.9 - Construction Safety and Health Program

- 5632.8 - Physical Protection of Classified Matter

\subsubsection{Other Government Regulations}

The following Government Regulations are applicable to the Laser System.

- 29 CFR 1910.7 - Definitions and Requirements for a Nationally Recognized Testing Laboratory (NRTL)

- 29 CFR 1910 - Occupational Safety and Health Act (OSHA) - Operation

- 29 CFR 1926 - Occupational Safety and Health Act (OSHA) - Construction

- FED-STD-209E - Airborne Particulate Cleanliness Classes in Cleanrooms and Clean Zones

\subsection{Applicable National Consensus Codes and Standards}

The following National Consensus Codes and Standards are applicable to the Laser System.

- American National Standards Institute (ANSI):

$$
\text { - ANSI Z136.1 - 1993, Laser Safety }
$$

- DOE-STD-1020-94, Natural Phenomena Hazards Design and Evaluation Criteria for DOE

- American National Standards Institute (ANSI):

- $\quad$ ANSI B40.1 - 1991, Gauges-Pressure, Indicating Dial Type Elastic Element

- $\quad$ ANSI MC96.1 - 1982, Temperature Measurement Thermocouples

- $\quad$ ANSI/IEEE STD 241 - 1991, IEEE Recommended Practice for Electric Power Systems in Commercial Buildings

- $\quad$ ANSI C2 - 1993, National Electric Code

- $\quad$ ANSI C84.1 - 1989, Electrical Power Systems and Equipment-Voltage Rating (60 HZ)

- $\quad$ ANSI/NFPA 110-1993, Standard for Emergency and Standby Power Systems

- $\quad$ American Society for Testing and Materials (ASTM):

- ASTM C150 - 1995, Standard Specification for Portland Cement

- $\quad$ ASTM C33 - 1993, Standard Specification for Concrete Aggregates

- $\quad$ ASTM C94 - 1994, Standard Specification for Ready-Mixed Concrete

- $\quad$ ASTM C260 - 1994, Standard Specification for Air-Entraining Admixtures

- $\quad$ ASTM C494 - 1992, Standard Specification for Chemical Admixtures for Concrete 
- $\quad$ ASTM C618 - 1994, Standard Specification for Fly Ash and Raw or Calcined Natural Pozzolan for Use as a Mineral Admixture in Portland Cement Concrete

- $\quad$ ASTM A615 - 1995, Standard Specification for Deformed and Plain Billet-Steel Bars for Concrete Reinforcement

- $\quad$ ASTM A416 - 1994, Standard Specification for Steel Strand, Uncoated Seven-Wire Stress Relieved for Prestressed Concrete

- $\quad$ ASTM A36 - 1994, Standard Specification for Structural Steel

- $\quad$ ASTM A307 - 1994, Standard Specification for Carbon Steel Bolts and Studs, 60,000 psi Tensile Strength

- $\quad$ ASTM A325 - 1994, Standard Specification for High Strength Bolts for Structural Steel Joints

- $\quad$ ASTM A449 - 1993, Standard Specification for Quenched and Tempered Steel Bolts and Studs

- $\quad$ ASTM A490 - 1993, Standard Specification for Heat-Treated Steel Structural Bolts, 150 ksi Minimum Tensile Strength

Recommendations

- UCRL 53526 Rev 1 - Natural Phenomena Hazards Modeling Project for Department of Energy Sites (1985)

- UCRL 53582 Rev 1 - Natural Phenomena Hazards Modeling Project for Department of Energy Sites (1984)

- DOE-STD-1021-93, Natural Phenomena Hazards Performance Categorization

Guidelines for Structures, Systems, \& Components.

- $\quad$ Uniform Building Code (UBC) 1994

- $\quad$ NFPA 72 1993, National Fire Alarm Code

- $\quad$ NFPA 70 1996, National Electric Code

- IEEE 493 1990, IEEE Recommended Practice for the Design of Industrial and Commercial Power Systems

- $\quad$ NFPA 101 1994, Code for safety to Life from Fire in Buildings and Structures

\subsection{Applicable LLNL Standards}

Pending final site selection, the following LLNL standards apply to the Laser System, as specifically referenced in later sections.

LLNL M-012 Rev 7, Feb. 1993, "Design Safety Standards -Mechanical Engineering"

LLNL M-010, March 1989, "Health and Safety Manual"

LLNL M010, "Hazards Control Manual"

LLNL M-256 "Mechanical Engineering Design Practice"

\subsection{System Definition}

The NIF Laser System is designed to support ICF experiments with the goal of fusion ignition. Weapons physics experiments, radiation effects simulation, and other experiments including high energy density science and inertial fusion energy will also be conducted as permitted by the system design. The Laser System is defined as the special equipment that generates and delivers high-power optical pulses to the target chamber, from optical pulse generation through the final optics assemblies. It includes supporting structures, optical components and the laser control system and auxiliary systems.

Within the Laser System, laser light is produced at these nominal wavelenths, defined as follows:

$1 \omega-1.053 \mu \mathrm{m}$ nominal wavelength

$2 \omega-0.527 \mu \mathrm{m}$ nominal wavelength

$3 \omega-0.351 \mu \mathrm{m}$ nominal wavelength 


\subsubsection{System Description}

The Laser system is configured in a four pass architecture with a laser pulse injection into the output Spatial Filter.

The beams are arranged in groups of contiguous beams packed in an array that is four beams high. A total of 192 beams will be deployed. The master oscillator in pulse generation creates an initial optical signal which is temporally shaped and distributed to individual beam line amplifiers. The preamplifier is a compact standalone package with a nominal gain of $10^{10}$. It also spatially stages and provides the aperture which is optically relayed through the remainder of the laser optical system. The beam is then injected into the far field of the transport spatial filter, which directs the beam through the boost and cavity amplifiers in a multi-pass scheme that minimizes the energy required for initial injection. The nominal hard aperture size is $40 \mathrm{~cm}$, a compromise between risk and system cost. Amplifier flashlamps uniformly pump the amplifier slabs. The power conditioning system providing this power utilizes banks of dielectric capacitors. Switch-out of the pulse from the amplifier cavity is accomplished with the Plasma Electrode Pockels Cell (PEPC) switch that operates at high efficiency.

After passing through the booster amplifier and transport spatial filter the $1 \omega$ beams are directed to the target chamber using a number of high-reflectivity mirrors. At the chamber the beams are directed to either an inner or outer cone array. Clustered into groups of four contiguous beams, they are directed through the final optics system. Within each final optic system the frequency of each beam is tripled by using a KDP crystal and a KD*P crystal, then focused onto the target with the focusing lens. After the beam is focused, it is then phase modulated using a kinoform phase plate prior to target irradiation.

During the transport of each laser beam from the preamplifier to the target, precision systems provide for the beam alignment, and the measurement of beam spatial and temporal characteristics.

Optical components of the laser system comprise those large, custom designed and fabricated for amplification and transport of the full aperture NIF beam. Included in this category are; laser slabs, injection, cavity and transport mirrors, optical switch crystals and polarizer, spatial filter lenses, frequency conversion crystals, vacuum windows for the Pockels cell, focus lens and the debris shield/phase plate.

The Laser is composed of elements of five Level 2 WBS systems. The level 3 WBS elements which are covered by this SDR document are listed below, and are functionally described in Section 3.1.5. Note that not all Laser Level 3 WBS elements have been designated major subsystems for the purpose of controlling Laser System configuration requirements.

1.3.1 Optical Pulse Generation System

1.3.2 Amplifier System

1.3.3 Pockels Cell System

1.3.4 Amplifier Power Conditioning System

1.3.5 Laser Auxiliary Systems

\subsubsection{Beam Transport Enclosures}

1.4.2 Interstage Subsystems

1.4.3 Support Structures

1.4.4 Optomechanical Systems

1.6.1 Amplifier Slabs

1.6.2 Lenses

1.6.3 Mirrors

1.6.4 Polarizers

1.6.5 KDP and KD*P Crystals

1.6.6 Debris Shields and Windows

1.6.7 Pulse Generation Optics

\subsubsection{Alignment Systems}


1.7.2 Beam Diagnostics

1.7.3 Wavefront Control Systems

\subsubsection{Final Optics Assemblies}

\subsubsection{System Functions}

The overall functions of the Laser System are listed below. Specific requirements are listed in Sections 3.2-3.6.

- Provide capability to routinely produce a high-quality, $1.8 \mathrm{MJ}$, temporally-shaped optical pulse at $3 \omega$ frequency, incident on the entrance hole of the target hohlraum.

- Provide capability of producing a pulse with peak power of at least $500 \mathrm{TW}$.

- Produce laser-wavelength of 0.35 micro-meters $(\mu \mathrm{m})$.

- Provide for an RMS deviation in power delivered by the beams from the power specified, averaged over any 2 nanoseconds (ns) time interval, of less than $8 \%$.

- Provide a beam pointing accuracy with RMS deviation of less than $50 \mu \mathrm{m}$ in the target plane.

- Capable of producing a pulse with overall duration of up to $20 \mathrm{~ns}$ in an individual beamline.

- Provides capability of delivering pulses to the fusion/target with a dynamic range of at least 50:1, where dynamic range is defined as the ratio of intensity at the peak of the pulse to the intensity in the initial "foot" portion of the pulse.

- Provide for focusing of the beam onto the target.

The functions of the major subsystems of the Laser are described in Section 3.1.5, Major Subsystems of this document.

\subsubsection{System Diagrams}

\subsubsection{System Operating Modes}

Figure 3.1.3.1-1 identifies the sequence of operating modes planned for the NIF facility. The laser system will also operate in all these modes, following the same scenario as the overall facility. 


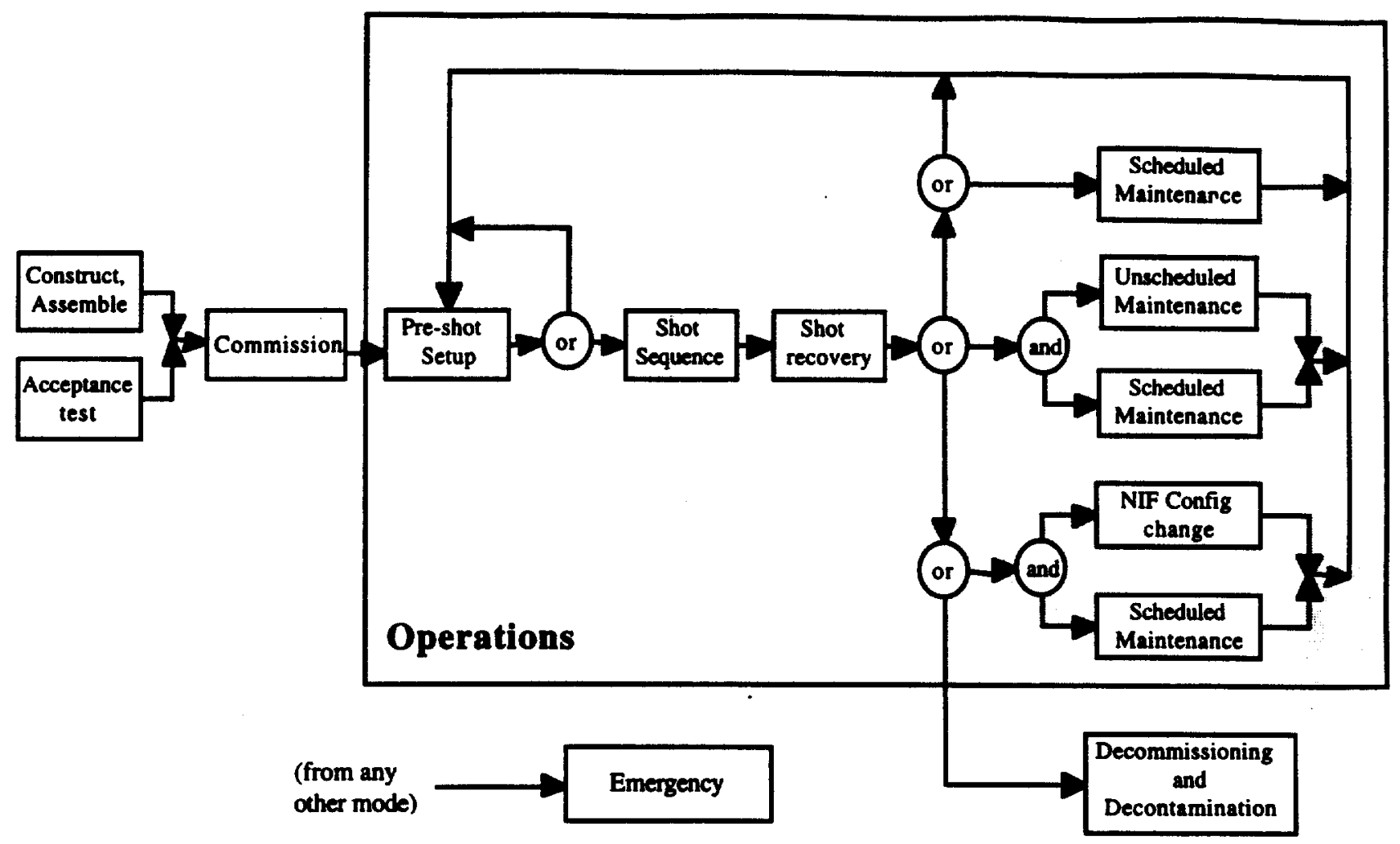

\subsubsection{Primary Interfaces}

Figure 3.1.3.1-1 NIF operating modes.

The Laser system has major interfaces with:

Laser and Target Area Building WBS 1.2.2.1/2 - The Laser interfaces with the Laser Building in the general arrangement, at physical support points, environmental control, in provision of utilities, in installation, operation and maintenance.

Optics Assembly Building WBS 1.2.2.3 - The Laser System components are received, inspected, cleaned, assembled, tested and stored in the Optics Assembly Building.

Integrated Computer Control, WBS 1.5 - The computer controls provide timing and control signals, alignment and supervisory control for target area systems. The laser systems provide various diagnostic data to the integrated controls.

Target Experimental System, WBS 1.8 - The laser system interfaces mechanically with the target area system at the mounting points for the final optic assembly and Beam Transport mirrors in the Target Area. The laser provides laser energy with appropriate properties for conducting experiments. The Target Area System provide diagnostics of target performance, experimental targets, and physical support for final optic assemblies.

Interface Control Documents (ICDs) describe the functional and physical interfaces between WBS Level 3 subsystems, and are controlled separately from System and Subsystem Design Requirements (SDRs and SSDRs). ICDs control: 1) interfaces between subsystems which are both within the Laser System, and 2) interfaces between subsystems within the Laser System and subsystems outside the Laser System. The document control system will contain the approved list of ICDs and the present revision of each. 


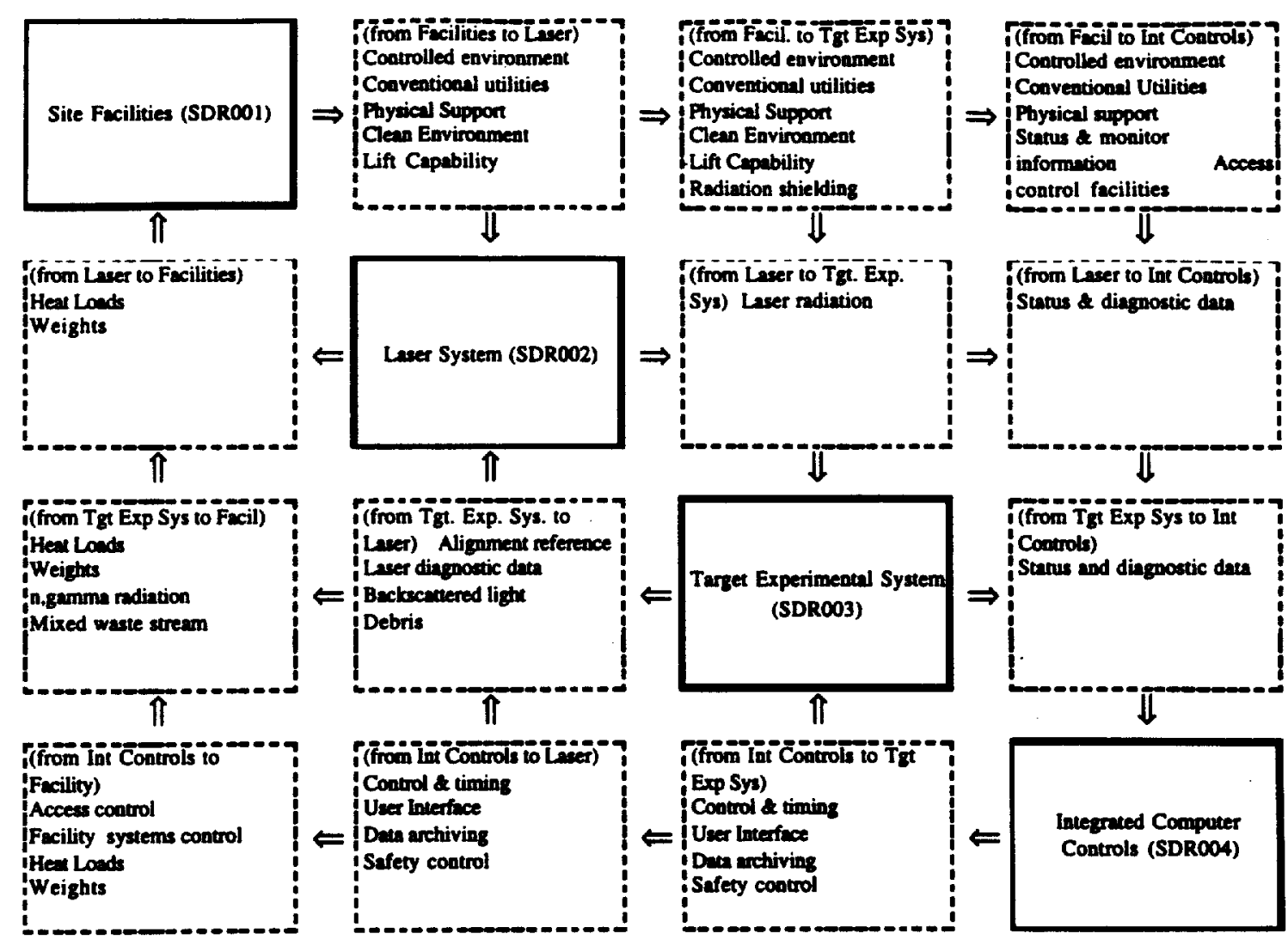

NIF System Functional Relathonchip Diagram

(Hocizontal anows are outputs, Vertical arrows are inputs)

Figure 3.1.4.1 - Functional Relationship Diagram

\subsubsection{Major Subsystems}

The Laser System is composed of thirteen major elements:

Optical Pulse Generation System

Amplifier System

Pockels Cell System

Amplifier Power Conditioning System

Laser Auxiliary Systems

Beam Transport Enclosures

Interstage Subsystems

Support Structures

Optomechanical Systems

Alignment Systems

Beam Diagnostics

Wavefront Control Systems

Final Optics Assemblies

\subsubsection{Optical Pulse Generation System WBS 1.3.1 \& 1.6.7}

The Optical Pulse Generation (OPG) System produces the $1 \omega$, temporal and spatial smoothed formatted pulses with the correct energetics and optical characteristics required for injection into the main amplifier Transport Spatial Filter on an individual beamline basis. The initial pulse is generated by the master oscillator, temporally shaped in the amplitude modulator and transferred to each preamplifier module (PAM) via fiber optic cable. The 
PAM is a two-stage amplifier consisting of a regenerative amplifier stage followed by a beam shaper spectral dispersion smoothing section and a multi-pass cavity. The pulse is optically matched (e.g., f/Number, focus location, image relay, etc.) to the main amplifier and spatially filtered by the preamplifier beam transport subsystem (PABTS).

\section{Functions of the Optical Pulse Generation System}

- Generate and deliver to the main laser cavity injection point, on an individual beamline basis, optical pulses with the following characteristics:

- a wavelength at which the laser gain is maximum (approximately $1.053 \mu \mathrm{m}$ )

- variable pulse lengths

- spatial shaping capability

- gain sufficient to amplify with high fidelity the spectral, temporal and spatial signals generated to the several Joule level

- optically transport and format the beam to meet the basic optical system requirements of the main amplifier (e.g., wavefront, beam shape, f/Number, focus location, image relay, polarization, and spatial-intensity-profile orientation).

- Provide a pulsed, several milliwatt beam on a continuous basis to the laser system for component alignment and beam diagnostics calibration purposes.

- Provide a "typical drive pulse" of several joules energy to the laser system for component alignment and beam diagnostics calibration purposes.

- Adjustable output energy and temporal pulse shape to allow for balancing of the beamline outputs.

- Variable beamline intensity profile to compensate for gain roll-off in specific beamlines due to geometric factors in the two dimensional packing of beamlines in a beam bundle.

- Adjustable time delays for each beam line to allow synchronization of pulse arrival times on target.

- Produce temporally and spatially shaped and sequenced pulses on specified beamlines for target backlighting applications.

\subsubsection{Amplifier System WBS 1.3.2 \& 1.6.1}

The Amplifier consists of the hardware required to provide laser gain (increased optical pulse energy). It includes the mechanical assembly to support the Nd glass slabs, blast shields, covers for operational protection, the reflectors and the flashlamps. The Pulse Power needed to drive the lamps is covered in the Power Conditioning section.

\section{Amplifier system functions}

- Provide for the efficient pumping of the laser slabs by the flashlamps.

- Provide necessary gain of the required spatial uniformity, and mitigates the spatial amplitude variations in the beam.

- Provide a mechanically stable housing that allows for ease of maintenance.

- Allow for contamination control in the pump cavity. 


\subsubsection{Pockels Cell System WBS 1.3.3, 1.6.5.1 \& 1.6.6.3}

The Pockels Cell Assembly working in conjunction with the Polarizer, functions as the optical switch in the main amplifier cavity. During a laser shot, the switch is closed by turning the Pockels cell on, which captures the optical pulse in the amplifier cavity allowing for multipass amplification. When the Pockels cell is in the "on" state, the polarization of the light allowed to pass through it is rotated 90 degrees. This aligns the light polarization with the polarizer. The beam then passes through the polarizer toward the second cavity end mirror, reflects off the mirror, and returns to the amplifiers for additional gain passes. During the final pass, the switch is opened by turning the Pockels cell off. The polarization of the beam is not rotated so the beam now reflects off the polarizer and is reflected out of the amplifier cavity.

Pockels Cell Functions:

- When turned on, the Pockels Cell assembly rotates the polarization of a linearly polarized incoming beam by 90 degrees.

- When turned off, the Pockels Cell assembly does not alter the polarization of the incoming beam.

\subsubsection{Amplifier Power Conditioning System WBS 1.3.4}

The Power Conditioning system provides pulsed electrical power to drive the flashlamps in the laser cavity and booster amplifiers. Electrical energy from the utility power line is converted to stored energy in high voltage capacitors over a period of roughly one minute. High power switches and transmission lines then discharge the capacitors with a specified pulse shape into the flashlamps.

The Power Conditioning system functions are:

- Provide electrical pump energy to flashlamps in the laser amplifiers including capacitor charging, energy storage, switching, and power transmission

- Provide adjustment of pump energy over specified range

- Pre-ionize flashlamps a few hundred microseconds prior to a shot

- Provide low energy "lamp check" shots to verify system integrity

- Provide controls and diagnostics for the following functions: charging supplies safety energy dump system, interlock permissive timing delays and triggering lamp current diagnostics during both normal and "lamp check" shots system diagnostics and maintenance

\subsubsection{Laser Auxiliary Systems WBS 1.3.5}

Laser auxiliary systems provide low conductivity water, electrical support, compressed air and working gas required for laser system operations. They also provide an inventory and control system designed to keep replacement parts readily available to reduce downtime as well as personnel transporters for maintenance and repair access in hard to reach areas of the laser system. An important element of the laser auxiliary systems is the clean gas system which is essential to the proper function of the Amplifiers.

Laser auxiliary systems functions include:

- Provides support elements for laser system function and operability.

- Allows personnel access to otherwise inaccessible areas for repair and maintenance of the system by use of personnel transport systems, i.e.: hydraulic manlift.

- Provides a clean gas supply for the proper function of internal amplifier components. 


\subsubsection{Beam Transport Enclosures WBS 1.4.1}

The Beam Transport Enclosures consist of beam tubes or vessels that contain the laser beam from beam injection at the transport spatial filter to the target bay wall. Beam transport enclosures include the transport and cavity spatial filters, the interstage beam enclosures, and the switch yard beam enclosures. Sections of the enclosures may be under vacuum or filled with noble gas to prevent stimulated rotational raman scattering (SRRS).

The functions of the beam transport enclosures are to:

- safely contain laser beam within an appropriately controlled environment to minimize temperature induced density gradients and practice contamination.

- provide access for optomechanical system maintenance and removal of optic assemblies

- provide ports for beam injection and diagnostics

- provide required stability for optics mounting

\subsubsection{Interstage Subsystems WBS 1.4.2}

Interstage Subsystems (Beam Transport Auxiliary Systems) provide utilities, vacuum systems, local rigging, local clean rooms, and optics handling systems.

Beam transport is accomplished by propagation through beam tubes. Interstage subsystems maintain the gaseous environment in the switchyard beam tubes and the evacuated environment in the spatial filters. Clean backfill systems are also provided for spatial filters, providing control of temperature and particle contamination.

Switchyard beam tubes will be filled with a noble gas to prevent stimulated rotational raman scattering (SRRS). The temperature of the gas in these tubes will be controlled to the level of the facility temperature and delivered sufficiently clean so that overall optics cleanliness requirements are met.

\subsubsection{Support Structures WBS 1.4 .3}

The Laser and Beam Transport Structural Support Systems (LBTSSS) support the hardware that transports the beam through to the target chamber area. The beams are arranged in $4 \times 2$ groups in the laser area, and split into $2 \times 2$ groups in the switchyards. Each beam has an independent, turning mirror for every turn required.

Amplifiers, polarizers, mirrors, pockels cells, and spatial filters are contained in assemblies which, in turn, attach to the WBS 1.4 .3 support structures.

The support structures;

- Mechanically support beam tubes, and optomechanical systems.

- Provides a support structure that maintains high, positional stability. 


\subsubsection{Beam Transport Optomechanical Systems WBS 1.4.4, 1.6.2, 1.6.3, 1.6.4, 1.6.6.2} \& 1.6.6.4

The spatial filter is a confocal lens pair with a pinhole located in their common focal plane. The beams low frequency spatial modes pass through the pinhole while the high frequency modes are removed by the region exterior to the pinhole. Laser alignment and diagnostics are accomplished in the transport filter. The preamplifier laser pulse is injected into the transport filter.

The optical pulse generator delivers the input beam through a vacuum window in the Transport spatial filter. The spatial filter then utilizes a system of small aperture optics to route the input beam through the spatial filter pinhole, and into the amplifier cavity.

The cavity mirror mount assemblies, located at both ends of the laser cavity, provide support and remote alignment of the cavity mirrors. These mirrors reflect the beam back and forth to accomplish multi-pass amplification. The transport tuming-mirror mounts provide support and alignment of the mirrors that transport the beam from the laser cavity to the target. The NIF polarizer mount assembly provides support and remote alignment of the polarizer plate at Brewster's angle. The polarizer plate works in conjunction with the Pockels cell to switch the beam out of the laser cavity after four-pass amplification.

\section{Cavity Mirror Mount Assemblies}

- Provide support and remote alignment of the cavity mirrors.

- These mirrors reflect the beam back and forth to accomplish multi-pass amplification.

\section{Transport Turning Mirror Mounts}

- Provide support and remote alignment of the transport mirrors.

- The mirrors transport the beam from the laser cavity to the target.

Polarizer Mount Assembly

- Provides support and remote alignment of the polarizer plate at Brewster's angle.

- The polarizer plate works in conjunction with the Pockels Cell to switch the beam out of the laser cavity after four-pass amplification.

Spatial filter optical assemblies:

The functions of the spatial filters are:

- Allows for removal of high spatial frequency modes to reduce the risk of damage to the large, expensive optics.

- Provides the beam dump for absorption of excess beam energy.

- Provides small aperture locations for laser alignment and diagnostics.

- Provides a method for injecting a low energy pulse into the high-gain amplifier cavity. 


\subsubsection{Alignment Systems WBS 1.7.1}

The alignment systems comprise optical, mechanical, electronic, and control components that measure beam position, direction, and size in key locations; calculate errors in alignment or focus; and implement automatic adjustments of beam transport components to bring the errors within tolerance.

Optimum performance of the laser depends on accurate alignment. Centering the beam on the optical axis of an amplifier, for example, minimizes clipping and helps to obtain maximum output energy without unnecessary spatial intensity modulation. It is important for such tasks to be automated because there are more than 7,000 actuators that must be adjusted for maintenance of alignment alone.

Accurate positioning of the laser output on the target is critical for achieving designed target performance because the target is very sensitive to details of its illumination. Stand-alone capability for classified target alignment is provided to the extent that additions are required to the unclassified systems.

In general, the alignment systems must establish and maintain the correct relationships between beam position, beam angle, laser component clear apertures, and the target. At the target this includes adjustment of beam focus to obtain the correct spot size. This must be accomplished on all beams in a time consistent with planned shot rates. Components required for installation, activation, and initial operation independent of control from the integrated control systems are also included.

Alignment and other beam control and laser diagnostic functions are distributed throughout the laser system. The figure below identifies their principal locations in a single NIF chain.

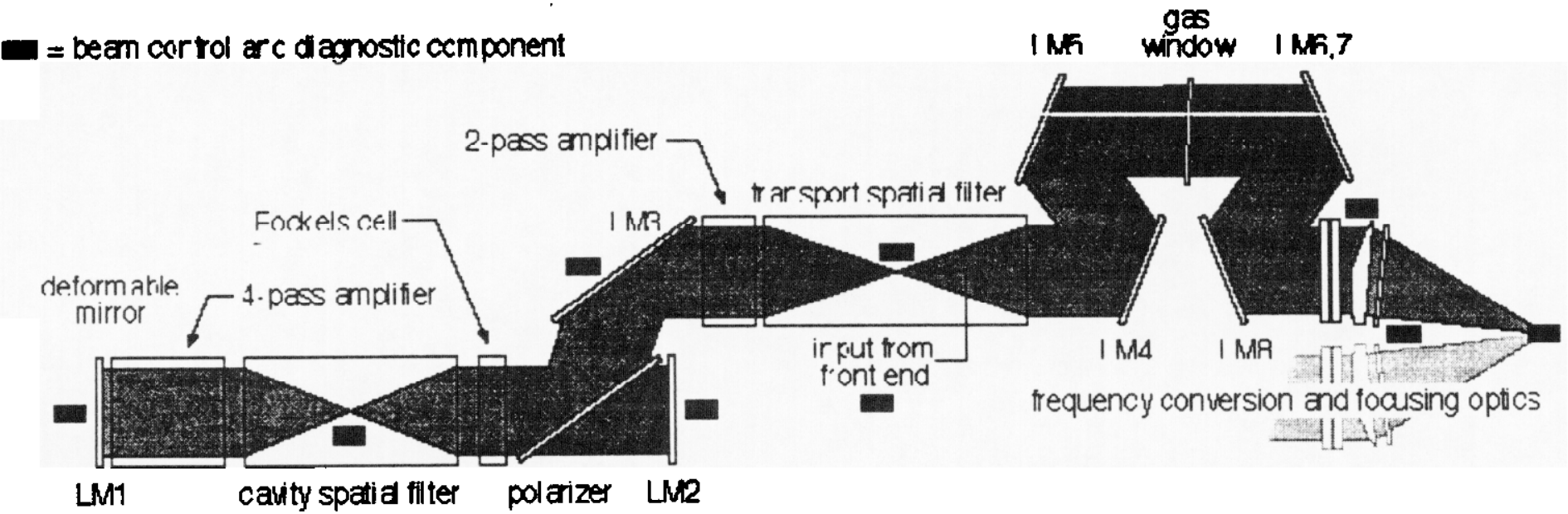

Locations for beam control and laser diagnostics components are distributed throughout the laser chain. 


\subsubsection{Beam Diagnostics WBS 1.7.2}

The beam diagnostics comprise optical, mechanical, electronic, and data processing components that measure laser energy, power, and spatial intensity distribution in key locations.

These measurements provide the basis for tuning the laser to produce the precise output characteristics required by each target. Automated comparisons between the achieved performance and the desired results define the set of adjustments to be implemented before the next shot.

Accurate measurement of beam characteristics is also important for proper modeling of target experiments since target performance is very sensitive to details of its irradiation. To the extent possible, it is desirable to measure the properties of each beam going to the target on each target shot.

Processing of the data collected on each shot must be accomplished quickly enough to provide feedback for adjustment prior to the next shot at the maximum shot rate.

\subsubsection{Wavefront Control System WBS 1.7.3}

The wavefront correction systems comprise optical, mechanical, electronic, and control components that measure the wavefront at the output of each laser chain, calculate the error by comparing the measured and desired wavefronts, and implement automatic adjustments of the deformable mirror to bring the errors within tolerance.

Optimum performance of the frequency converter and proper focusing of the beam on the target depend on meeting wavefront requirements. The adjustment of even one deformable mirror by an operator is difficult, and for a 192-beam system the task must be automated.

Optimization of the wavefront for each shot is based partly on current information and partly on information from previous shots. Correction for static errors due to fabrication, slowly varying thermally induced errors, and errors due to gradients in the gas path through which the beam is propagating is based on real-time measurement in the period before a shot. Correction for amplifier aberrations induced at shot time is based on measurements of these effects from previous shots.

\subsubsection{Final Optics Assemblies WBS 1.8.7, 1.6.2.3, 1.6.5.2, 1.6.5.3, 1.6.6.1, 1.6.6.5,} 1.6.6.6

The final optics system includes all mounting hardware, 2-axis precision positioners for the KDP crystals, a z-axis translation stage for each lens, and all support structure required to maintain high positional stability of the optics at the target chamber.

The Final Optics system converts $1 \omega$ beams to the third harmonic through use of KDP/KD*P frequency conversion crystals that are mounted in partial vacuum within the final optics tubes attached to the target chamber. After passing through a vacuum barrier window, the $1 \omega$ input beam is converted to $1 \omega, 2 \omega$, and $3 \omega$ by the KDP crystals. After conversion, each beam passes through a $700 \mathrm{~cm}$ focal length lens and finally the debris shield. A kinoform phase plate conditions each beam. Each of the four contiguous beams are transported in a group and focused to the same location near the target. The wedge in the focus lens bends the $1 \omega$ and $2 \omega$ residual light away from the target laser entrance hole preventing unwanted light in the target 
Final Optics Functions;

- Converts $1 \omega$ beam frequency to the third harmonic $(3 \omega)$.

- Provides for mounting of the focal lens, debris shields and kinoform phase plate facilitating beam smoothing.

- Disperses the $1 \omega$ and $2 \omega$ residual beams keeping them from entering the target laser entrance hole.

- Conditions the $3 \omega$ beam.

- In conjunction with Final Focusing Lens, focuses each of the four beams onto a common focal area near the target.

- Provides a vacuum barrier for the target chamber.

\subsection{Requirements and Verification}

\subsubsection{Performance Characteristics}

\subsubsection{Laser Energy and Power}

\subsection{Routine Operating Energy and Power}

The Laser System shall routinely produce a temporally-shaped $3 \omega$ pulse, with a total energy of $1.8 \mathrm{MJ}$ and a peak power of $500 \mathrm{TW}$ at the target plane or its equivalent. These requirements apply under the following conditions:

- temporal pulse shape as shown in Figure 3.2.01-1, the "Haan pulse"

- laser wavelength is line center, $1.053 \mu \mathrm{m}(1 \omega)$

- 1 angstrom bandwidth at $1 \omega$, undispersed

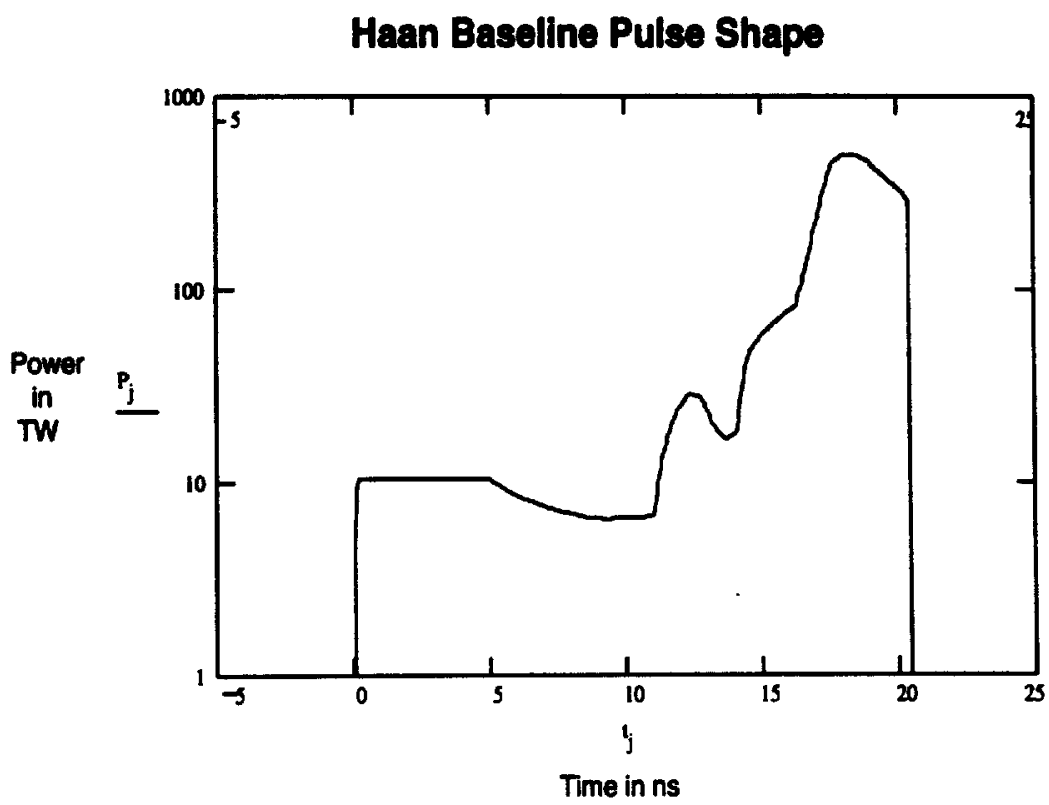

Figure 3.2.1.01-1 The "Haan pulse" Temporal Shape 


\subsection{Maximum Design Energy and Power}

The laser shall be capable of producing a temporally-shaped $3 \omega$ pulse with a total energy of $2.2 \mathrm{MJ}$ and a peak power of $600 \mathrm{TW}$ at the target plane or its equivalent. These requirements apply under the same conditions as 3.2.1.01.1.

\subsection{Operating Energy and Power Envelope}

The Laser System shall be capable of routinely producing any combination of $3 \omega$ power and energy within the shaded region of Figure 3.2.1.01.3-1, within the normal shot-to-shot turn-around time.

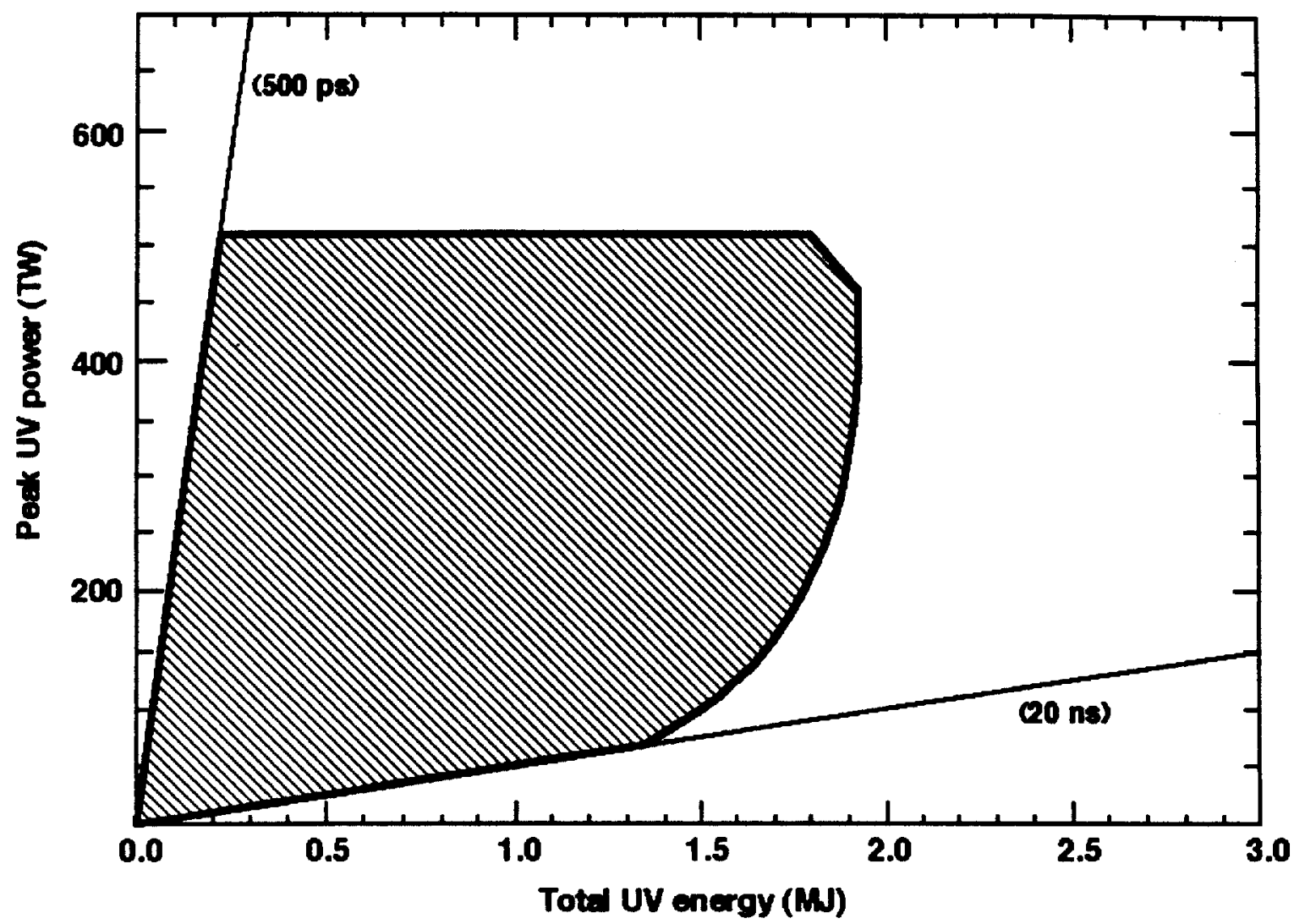

Figure 3.2.1.01.3-1 Laser System 3 $\omega$ Power/Energy Envelope.

\subsubsection{Laser Pulse Wavelength}

The wavelength of the laser pulse delivered to the target shall be $0.35 \mu \mathrm{m}$. As a design goal, the laser should not preclude delivering $0.53 \mu \mathrm{m}$ and $1.053 \mu \mathrm{m}$ wavelength light to the target with straightforward modifications.

\subsubsection{3 $1 \omega$ Wavelengths}

The $1 \omega$ laser shall provide light at the wavelength of maximum gain, $1.053 \mu \mathrm{m}$. The design shall not preclude future implementation of multi color wavelength operation at up to four separate $1 \omega$ wavelengths from 1.0523 $1.0553 \mu \mathrm{m}$.

\subsubsection{Power Balance}

The rms deviation in the power delivered by a laser beam from the specified power shall be less than $8 \%$ of the specified power averaged over any 2-ns time interval. 
The total energy delivered by the system (all fired beams) shall be within $+3 \%$ of that specified. The simultaneity of beam arrival at target chamber center shall be $+30 \mathrm{ps}$.

\subsubsection{Beam Positioning Accuracy and Stability}

The rms deviation in position of the centroids of all beams from their specified aiming points shall not exceed 50 microns at the target plane or its equivalent. The Laser System interacts with the Target Experimental System to collectively meet the pointing accuracy and alignment stability requirements. Allowed inaccuracies and instabilities are allocated to key subsystems, and are defined in appropriate SSDR documents.

\subsubsection{Laser Pulse Duration}

The laser shall be capable of illuminating targets with laser pulses of 500 ps to 20 ns duration, with power and energy within the overall operating envelope. The Laser System shall be capable of diagnosing optical pulses longer than $1 \mathrm{~ns}$ in the target chamber for each beam. The Laser System shall further be capable of diagnosing pulses of any duration within the above-stated range from individual beams at an equivalent target plane.

\subsubsection{Laser Pulse Dynamic Range}

The laser shall be capable of delivering pulses to the fusion target with dynamic range of at least 50:1, where dynamic range is defined as the ratio of intensity at the peak of the pulse to the intensity in the initial portion of the pulse.

\subsubsection{Capsule Irradiation Symmetry}

The Laser System shall provide appropriate target irradiation symmetry for indirect-drive experiments as defined below. The Laser system shall not preclude future upgrade to achieve the direct-drive irradiation symmetry described below.

For indirect-drive experiments, the laser shall provide two-sided laser illumination of the hohlraum. Multiple laser beams on each side shall enter the hohlraum along two concentric cones with cone half-angles of approximately 27 degrees and 48 degrees, and with two-thirds of the beams on the outer cone and the remaining one-third on the inner cone. Each cone shall consist of 8 or more 4-beam "quads".

For direct-drive experiments, the Laser System shall not preclude the addition of a third cone of beams, concentric with the two indirect-drive cones, but with a cone half-angle of approximately 77 degrees, and containing half of all the beams. For this mode of operation, the 27 degree and 48 degree cones would have one-sixth and one-third of the beam respectively. In order to not preclude this option, the Laser System, in concert with all other NIF systems, shall provide a conceptual design for the required beam transport to the target chamber and ensure that this transport can be accomplished by rearranging existing indirect-drive components or adding additional components.

\subsubsection{Pre-pulse Power}

The $3 \omega$ laser intensity delivered to the target LEH during the 20-ns interval prior to arrival of the shaped laser pulse shall not exceed $10^{8} \mathrm{~W} / \mathrm{cm}^{2}$.

\subsubsection{Laser Pulse Spot Size}

The laser spot size for any individual beam shall be $500 \mu \mathrm{m}$, to be defined as follows: The envelope of the laser pulse spatial intensity distribution shall approximate an eighth order super-Gaussian at best focus. The laser beam profile diameter at $\mathrm{e}^{-1}$ in intensity shall not exceed $500 \mu \mathrm{m}$, with $1.8 \mathrm{MJ}$ (total for all beams) of pulse energy contained within a circle of $600-\mu \mathrm{m}$ diameter at the target plane or its equivalent. The irradiance on the perimeter or outside the perimeter of a $3 \mathrm{~mm}$ diameter Laser Entry Hole should be less than $10^{14} \mathrm{~W} / \mathrm{cm}^{2}$. 


\subsubsection{Beam Smoothness}

The NIF shall have flexible beam smoothing capability for the suppression of laser plasma instabilities in indirect drive targets and potentially for the suppression of hydrodynamic instabilities if utilized for direct drive targets.

The capability shall include:

- phase plates at the output of the laser for the control of the spatial irradiance distribution on the target.

- 1D-Smoothing by Spectral Dispersion (SSD), 3 angstrom of bandwidth critically dispersed, with means for bypassing beam conditioning subsystems.

- not to preclude 2D-SSD with 5 angstrom of bandwidth critically dispersed, with means for operating with

ID-SSD as described above, and with means for bypassing beam conditioning subsystems.

- not to preclude operation at up to four different wavelengths with 1-D SSD, 3 angstrom of bandwidth critically dispersed or with beam conditioning subsystems bypassed.

\subsubsection{Annual Number of Shots with Fusion Yield}

The Laser System shall be capable of performing yield shots with a total DT fusion yield of $1200 \mathrm{MJ} / \mathrm{year}$. The Laser System shall be capable of performing up to 50 shots per year with a routine DT fusion yield of $20 \mathrm{MJ}$.

\subsubsection{Shot Turn-Around Time}

The shot turn-around time for Laser System shall be no more than 8 hours for no-yield shots. The Laser System shall not preclude future upgrade to achieve a shot tum-around time of 4 hours for no-yield shots. The shot turnaround time is defined as the minimum time required after a full-system, no-fusion-yield shot until the next shot can be taken. (It includes the time required to recover from a shot, perform maintenance that is required between every shot, prepare the system for a shot (including laser alignment and target insertion and alignment), and then actually execute the shot. This does not include the time for unplanned maintenance or for periodic shutdowns for planned maintenance.)

\subsubsection{Diagnostic Instrument Capabilities to Verify Laser Performance}

The Laser System shall have the following measurement capabilities which are required to verify the Primary Criteria and Functional Requirements:

- Measurement of the laser pulse energy and power.

- Measurement of the laser pulse duration and dynamic range.

- Measurement of laser beam power balance.

- Measurement of the simultaneity of arrival of pulses from individual beamlines at target chamber center.

- Measurement of the laser beam pointing accuracy.

- Measurement of laser prepulse intensity.

- Measurement of laser pulse spot size.

- Measurement of laser pulse smoothness.

\subsubsection{Laser Firing Flexibility}

As a design goal, the Laser System should provide maximum flexibility in the timing, sequencing, and temporal pulse shaping of separate laser beams.

\subsection{Bundle Firing Flexibility}

The Laser System shall be capable of firing an arbitrary operator-designated subset of the bundles on each shot, within the overall restriction of the shot turnaround time for each bundle or beam. 


\subsection{Beam Firing Flexibility}

The Laser System shall be capable of producing pulses from the four vertical pairs of beams within a given bundle at separate times, within an overall time window of $100 \mathrm{~ns}$.

\subsection{Beam Pulse Shape Flexibility}

The laser shall be capable of producing an operator-selected temporal pulse shape for each beam, within the overall operating envelope defined by other sections of this document, independent of all other beams.

\subsection{Laser Bay Operating Flexibility}

The laser system shall have the capability to fire laser beams in one laser bay with simultaneous safe manned access in the other laser bay and in the target area. For this requirement, "safe manned access" includes personnel physical access to the non-operating laser bay, power conditioning and target areas, the ability to work on all hardware in the non-operating laser bay, power conditioning and target areas, and the ability to work in the optical beam paths in the non-operating laser bay and target area.

\subsubsection{Beam Focusing and Pointing Flexibility}

The Laser System shall routinely place beam spots at arbitrary operator-designated positions within $\pm 30 \mathrm{~mm}$ of the target chamber center in three directions. The Laser System shall have the capability to routinely place subaperture beam spots at arbitrary operator-designated positions within $\pm 50 \mathrm{~mm}$ of the target chamber center in three directions, with minor modification. The Laser System shall be capable of placing beam spots at arbitrary operator-designated positions within $\pm 250 \mathrm{~mm}$ of the target chamber center in three directions, with future userprovided modifications of the final optic assemblies. 


\subsubsection{Management of Unconverted (1 $\omega$ and $2 \omega$ ) Light}

The unconverted $1 \omega$ and $2 \omega$ light shall be managed in the target chamber so as not to adversely affect the operation of the system or the experimental physics.

The final optics shall divert the unconverted $1 \omega$ light so that its geometrical optics edge is displaced at least $3.0 \mathrm{~mm}$ from the center of the LEH. The final optics shall divert the unconverted $2 \omega$ light so that its geometrical optics edge is displaced at least $1.76 \mathrm{~mm}$ from the center of the LEH.

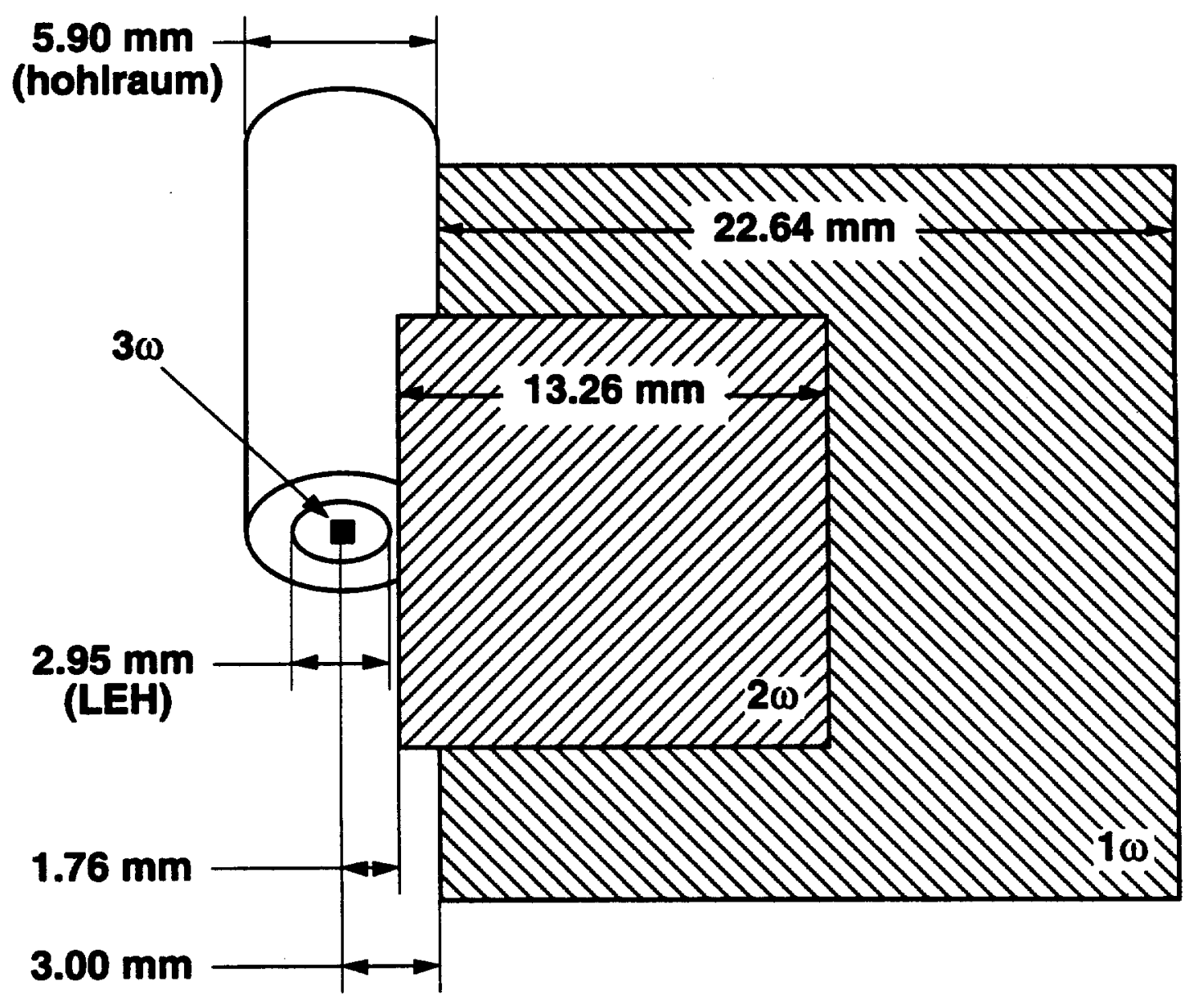

Figure 3.2.1.17-1 Nearest allowed location of unconverted $1 \omega$ and $2 \omega$ light at the target.

\subsubsection{Optical Clear Aperture}

The optical clear aperture of the amplifier shall be $400 \mathrm{~mm} \times 400 \mathrm{~mm}$.

The optical clear aperture of the frequency tripler shall be $400 \mathrm{~mm} \times 400 \mathrm{~mm}$; this is the limiting optical clear aperture in the final optics.

\subsubsection{Number of Beams}

The Laser System shall be composed of 192 beams.

\subsubsection{SRRS Suppression}


The laser system shall scatter no more than $1 \%$ of the $1 \omega$ power into Rotational Raman lines during transport from the output of the final spatial filter to the final optics assembly.

\subsubsection{Low-Power and Low-Energy Laser Pulses}

The laser system shall be capable of firing low-power and low-energy laser pulses without damage to any laser system components except beam dumps. Low-power and low-energy is defined for this requirement as including shots in which the flashlamps are fired, but no input pulse is injected.

\subsubsection{Experiment Compatibility}

\subsection{Classification Level of Experiments}

The Laser System shall allow both classified (at the SRD level) and unclassified experiments. The Laser System shall provide for alignment of classified (SRD) targets. As a design goal, the Laser System should minimize the cost and operational impact of changing classification levels.

\subsection{Future Upgrades for Other Users}

\subsection{Future Additional Target Chamber}

The design of the Laser System shall not preclude the future installation of an additional target chamber, employing all laser beams, for weapons physics and/or radiation effects testing. As a part of the NIF project, the Laser System, in concert with other NIF systems, shall provide a general arrangement layout for the addition of the target chamber. All Laser System designs shall be compatible with this design concept. All structural elements shall provide clearance for the identified future laser beam paths. Certain structures, such as building skins or shielding walls, require integrity to fulfill their functions prior to addition of the future target chamber; clearance for future beams is not required through such structures. However, their design shall be adequate that they will meet their requirements after addition of the future target chamber and associated beam clearances.

\subsection{Radiation Effects Testing Capability}

The baseline Laser System design shall incorporate basic capabilities so as not to preclude radiation effects testing by DNA or DOE, with future upgrade.

\subsection{Other User Needs}

As a design goal, the Laser System should accommodate requirements of other users with diverse needs.

\subsubsection{Laser System Grounding System}

The Laser System shall comply with the NIF Grounding Plan, NIF-LLNL-94-211, L-17346-1. Laser System components in the laser bay shall be isolated from those in the target bay, and separately grounded.

\subsubsection{Physical Characteristics}

\subsubsection{General Arrangement}

\subsection{Laser System Architecture}

The laser system shall incorporate the following basic architecture:

a. master-oscillator, power-amplifier system

b. conditioned pulses from master oscillator injected into the transport spatial filter near pinhole plane

c. four-pass amplification in cavity, with switch to allow pulse to enter and exit cavity

d. image relaying from serrated aperture 


\subsection{General Arrangement Drawings}

The Laser System shall conform to the drawings referenced in section 2.1 .2 which specify the general arrangement.

\subsubsection{Laser System General Configuration}

\subsection{Laser Bundles}

In the main laser chains, the laser beams shall be arranged in "bundles" that are four beams tall and two beams wide. Adjacent bundles shall be physically separated. The "main laser chain" is defined for this purpose as the laser equipment starting from injection into the transport spatial filter, through all amplifiers, Pockels cell, polarizer, etc., through and including the transport spatial filter output lens.

\subsection{Laser Quads}

The laser beams shall be arranged in "quads" of 2 beams wide by 2 beams for final transport to the target.

\subsection{Laser Clusters}

The Laser bundles shall be arranged in 4 clusters, each containing 6 bundles. The bundles within the clusters shall be nominally parallel, and shall have all major components at the same location in the direction of beam propagation (i.e., corresponding components in all bundles shall be at the same " $z$ " location in the laser bay coordinate system). The corresponding beams of each bundle shall be at the same elevation above the laser bay floor.

\subsection{Laser Bays}

The four laser clusters shall be arranged in two parallel bays, with two clusters in each bay. The two bays shall be arranged side-by side (as opposed to in-line), with corresponding laser equipment located at the same location in the direction of laser beam propagation ("z" axis in the laser bay coordinate system).

\subsubsection{Reliability, Availability, Maintainability}

\subsubsection{Lifetime}

The Laser System shall operate for 30 years.

\subsubsection{Replaceability}

Any portion of the Laser System which cannot reasonably be designed for 30-year lifetime shall be designed to be replaced or repaired at reasonable cost in a timely manner consistent with the overall availability of the System.

\subsubsection{Inherent Availability}

The Laser System shall have a shot availability of at least $97.44 \%$. The system is unavailable when it is undergoing unplanned maintenance. Unplanned maintenance includes failure detection and active repair as well as logistic and administrative downtimes. 


\subsubsection{Reliability}

The Laser System shall have an overall reliability of $82.66 \%$. Reliability is defined as the probability of meeting the minimum requirements of the experiment per no-yield shot. These requirements include:

3.2.1.1

3.2.1.4

3.2.1.5

\subsubsection{Maintainability}

The Laser System shall have a scheduled maintenance plan that fits within an overall annual plant goal of 69 days. The unplanned maintenance goal is 6.8 days per year. Opportunistic maintenance activities are performed between shots and during other system downtimes.

\subsubsection{Recovery from Abnormal Events}

The time required for the Laser System to recover from any abnormal event shall be less than the maximum times cited below, as a function of the expected yearly frequency of occurrence of the event.

\begin{tabular}{cc} 
Expected Frequency of Occurrence Per Year. $F$ & Maximum Recovery Time \\
\hline$F \geq 1$ & 24 hours \\
$1>F>1 E-2$ & 1 week \\
$1 E-2>F \geq 5 E-4$ & 3 months
\end{tabular}

Probabilities listed in DOE-STD-1020-94 shall be used for natural phenomena.

For frequent events, the maximum allowed recovery time may be restricted by availability requirements to be less than that shown in the table above.

\subsubsection{Environmental}

The site for NIF has not yet been selected. The present design is therefore non-site-specific. For the purpose of Title I design of the Laser System, it shall be assumed that NIF will be constructed at a site with the general infrastructure as available at candidate sites. Specific environmental assumptions are listed in the following sections.

\subsubsection{Operating Ambient Temperature/Humidity}

All Laser System components within the Laser and Target Area Building shall meet all requirements when operated at a temperature of $20^{\circ} \mathrm{C} \pm 0.3^{\circ} \mathrm{C}$, a relative humidity of $30 \%$ to $60 \%$, and a pressure equal to ambient atmospheric pressure $\pm 10 \mathrm{~cm}$ water (to accommodate positive/negative air systems). Any Laser System components normally operated outside the LTAB Building shall meet all requirements when operated between $4.4^{\circ} \mathrm{C}$ (dry bulb, winter) and $20.6^{\circ} \mathrm{C}$ (wet bulb, summer) or $37.8^{\circ} \mathrm{C}$ (dry bulb, summer), and local atmospheric pressure. 


\subsubsection{Ambient Cleanliness}

The Laser System shall meet all requirements when operated within the NIF LTAB. The ambient cleanliness levels in pertinent areas of the LTAB are as follows:

$\begin{array}{ll}\text { Area } & \text { Ambient Cleanliness Class } \\ \text { Laser Bay } & 100,000 \\ \text { Switchyard } & 100,000 \\ \text { Target Bay } & 100,000 \\ \text { MOR } & 100,000 \\ \text { Capacitor Bay } & \text { none (normal industrial housekeeping) } \\ \text { Operations areas } & \text { none (normal industrial housekeeping) }\end{array}$

\subsubsection{Ambient Random Vibration Environment}

The Laser System shall meet all requirements, while being exposed to ambient random vibration of $10^{-10} \mathrm{~g}^{2} / \mathrm{Hz}$, from 1 to $200 \mathrm{~Hz}$, applied at the special-equipment mounting surface of the foundation of the Laser or Target Area building.

\subsubsection{Back-Reflected Light}

The Laser System shall be resistant to major damage from back-reflected or scattered light.

\subsection{Design and Construction}

\subsubsection{Hazard Classification}

The NIF shall be designed and operated as a low-hazard, radiological facility. The inventory of key radionuclides shall not exceed the limits defined in the Preliminary Hazards Analysis, and cited below.

\subsubsection{Natural Hazards Classification}

Laser Systems shall meet the Performance Class 2 (PC2) design goals in DOE-1020.

\subsubsection{Radiation Protection}

The Laser System does not produce any radionuclides and therefore is not bound to an associated requirement.

\subsubsection{Safety}

The Laser System shall be designed, constructed, and operated as part of the NIF such that it is a low-hazard, radiological component of the NIF. Compliance with this classification shall be verified through a Preliminary Hazard Analysis assessment of bounding accidents involving those radionuclides and/or chemicals presenting the most significant hazards (see DOE Order 5481.1B, Safety Analysis Review System). Administrative controls shall be established prior to CD3 to ensure that inventory limits for a radiological low-hazard, non-nuclear facility are not exceeded.

Unless otherwise specified herein, all elements of the Laser System shall meet the requirements of the LLNL Mechanical Engineering Design Safety Standards, Electrical Engineering Design Standards, and laser safety standards.

\subsubsection{Life Safety}

Life Safety shall comply with DOE Order 420.1, Facility Safety. The Laser System shall have adequate means of egress, protection of vertical openings, travel distances, capacities, and emergency lighting. 


\subsubsection{Laser Safety}

All laser systems within the laser bay shall comply with requirements of ANSI Z136.1 regarding laser safety. Exposure to hazardous levels of laser light shall be prevented by the use of physical barriers, personnel training, interlocks, and personnel entry controls. Protective equipment, such as laser goggles, shall be used within the laser bay when necessary and feasible for operational purposes. Interlock systems shall be dedicated within the laser bay and designed to activate laser shutters or deactivate laser systems if access doors are opened.

Requirements of this paragraph also apply to systems within the laser bay that are required to protect workers from hazardous exposure to laser light from other systems.

\subsubsection{Occupational Safety}

Industrial hygiene and occupational safety shall comply with 29 CFR 1910 and DOE Order 440.1 , Worker

Protection Management for DOE Federal and Contractor Employees.

Construction safety shall comply with the requirements of 29 CFR 1926, OSHA and DOE Order 440.1, Worker Protection Management for DOE Federal and Contractor Employees.

Facility subsystems (e.g., vacuum systems, coolant supply, etc.) shall be designed to default to a safe state upon loss of power.

\subsubsection{Fail-Safe Design}

Wherever reasonably possible, Laser Systems shall be designed to fail safe upon inadvertent loss of power, accidental breach of isolated areas, or other failure.

\subsubsection{Fire Protection}

The Laser System shall be designed to meet the fire protection requirements of DOE order 420.1, Facility Safety.

\subsubsection{Cleanliness}

\subsubsection{Internal Optical Cleanliness}

The internal optical assemblies and their supporting elements shall be precision cleaned and assembled in a Class 100 clean room environment, per FED-STD-209D. During operation of the laser, the optical elements of the laser shall be maintained at a surface cleanliness level as defined by MIL-STD-1246C - Level 50. Permissible cleanliness degradation shall be budgeted across the assembly, measurement, transport, storage, installation and operation phases of laser construction. This budget is described in the document entitled, "Cleanliness Degradation Budgeting for the NIF Laser." The NVR (Non Volatile Residue) level for optical components shall conform to Level A/10 of MIL-STD-1246C or $1 \mathrm{mg} \mathrm{m}^{-2}$.

\subsubsection{General Cleanliness}

Wherever feasible, equipment to be deployed in the laser bays, switchyard, target bay, or other "clean" area shall be designed and constructed for class 10,000 clean room use, and shall be compatible with cleaning by aqueous solutions.

\subsubsection{Environmental Protection Requirements}




\subsubsection{Waste Management}

The Laser System shall minimize generation of hazardous, low-level radioactive, and mixed waste at the source, per DOE orders 5400.1, 5820.2A, and USC 6901 et. seq. All wastes are collected and disposed of in a manner meeting the requirements of: 40CFR260 (hazardous waste), 5820.2A (low-level radioactive waste), and DOE order 5400.3, and 40 CFR 260 (mixed waste). Low-level waste packages shall meet the solid waste acceptance criteria of the final approved disposal site.

\subsubsection{Effluents}

Liquid and gaseous effluents from Laser Systems shall be discharged through specifically identified NIF discharge points, where the discharges are monitored and controlled by Facility (WBS 1.2) systems. Contents of the discharges from the Laser System shall comply with the following standards: the Clean Water Act (33 USC 1251), conditions on the federal National Pollutant Discharge Elimination System (40 CFR 125), Sect 3.1 of the Clean Air Act (42 USC 7401), National Emissions Standards for Hazardous Air Pollutants, and state and local air quality management district requirements.

\subsubsection{Safeguards and Security}

The Laser System shall meet the requirements of DOE Order 5632.1C and DOE Order 470.1, during all stages of all classified experiments. This includes, but is not limited to: target viewing and alignment; and data acquisition and processing.

\subsubsection{Future Modifications and Upgrades}

As a design goal, the Laser System shall provide for future reconfiguration and modification at minimum cost and with minimum effect on the overall operation of the facility.

\subsubsection{Decontamination and Decommissioning}

The Laser System shall include considerations to allow cost effective future decontamination of radioactive contaminated structure and equipment and decommissioning of all structures and equipment. D\&D of the target area system shall be included in the overall NIF D\&D plan, which shall be prepared during Title 1 design. This plan shall be developed in accordance with DOE Order 5820.2A and 420.1

\subsubsection{Human Factors}

The Laser System shall be designed in an ergonometric fashion to ensure that human reliability during operation and maintenanence is sustained at a level consistent with meeting overall availability and reliability objectives. Consistency in displays, warnings, and human interfaces should be maintained throughout the Laser System and, if possible, throughout the NIF facility (i.e., GUI displays, access ports, tooling).

\subsubsection{Interchangeability}

Interchangeability of components shall be preserved as much as practical. Equipment with the same function and physical characteristics shall be interchangeable. 


\subsubsection{Documentation and Records}

The Laser System shall provide sufficient documentation to comply with the NIF Quality Assurance Plan, and DOE Order 5700.6C, Quality Assurance, Criterion-4 Documents and Records, which states: "Documents shall be prepared, reviewed, approved, issued, used and revised to proscribe processes, specify requirements or establish design. Records shall be specified, prepared, reviewed approved and maintained."

Examples of documents that should be controlled include drawings, data files, calculations, specifications, computer codes, purchase orders, vendor supplied documents, procedures, work records and data sheets and test records. Revisions should be reviewed by the organizations that originally prepared and approved the documents. Controlled documents should be distributed to those doing the work.

\subsubsection{Electrical Power}

Electrical Power shall be installed in accordance with NFPA 70, The National Electric Code, IEEE 493, Recommended Practices Design of Reliable Industrial and Commercial Power Systems and ANSI C2, the National Electrical Safety Code.

\subsubsection{Voltage Quality}

Voltage shall be maintained in compliance with ANSI C84.1, Electrical Power Systems and Equipment-Voltage rating $(60 \mathrm{~Hz})$. Electrical Systems shall operate in Range A of this specification. Voltage occurrences should not exceed Range B. Computers shall be protected with low voltage dropouts requiring manual restart.

\subsubsection{Design Processes}

Design shall be carried out using sound engineering principles and appropriate standards. Design work including changes shall incorporate applicable requirements and design bases. Interfaces shall be identified and controlled. The adequacy of design products shall be verified or validated by qualified individuals other than those who did the work. Verification and Validation work shall be completed before approval and implementation of the design.

\subsubsection{Supervisory Software Access to Distributed Control Points}

Access to all distributed control points that are integrated into the control system shall be made by Front End Processors that implement the hardware-level interface to the control points. The FEP software shall implement those functional requirements that are determined by requirements analysis to be allocated to the FEP layer in the controls architecture. The requirements analysis shall be guided by the physical properties and performance constraints of the control hardware, and by those operational scenarios requiring operation independent of the supervisory software or locality of control.

\subsection{Logistics}

\subsubsection{Spare Equipment}

As a part of the design/construction project, the Laser System shall provide an initial complement of spare parts as required to activate the system.

\subsubsection{Maintenance Equipment}

As a part of the design/construction project, the Laser System shall provide all equipment required to inspect, service, and maintain all subsystems within the Laser System to meet the maintainability and availability requirements in \$3.2.3. Maintenance equipment shall include all handling fixtures, lifting equipment, and other special tools not otherwise available within NIF, that are necessary to perform any planned (scheduled or unscheduled) maintenance activity. 


\subsubsection{Bottom-Access Maintenance}

As a design goal, all optical components within the full-aperture laser chains should be accessed for maintenance from below. This applies to all components in the laser chains from the injection mirror, through the deformable mirror, through the transport spatial filter lens.

\subsection{Major Subsystem Characteristics and Verification}

The purpose of Section 3.6 is to specify key subsystem characteristics and configuration items for the purpose of controlling these items at Change Control Level 3. This section does not include all requirements or characteristics of the major subsystems or their components, but only those whose characteristics must be controlled and systematically tiered down to the SSRD's. System Level includes all top level requirements, subsystem level requirements in the following sections apply independently.

Requirements that are included elsewhere in this document are not repeated in section 3.6.

\subsubsection{Optical Pulse Generation Characteristics and Verification (WBS 1.3.1)}

In addition to requirements flowed down from Sections 3.2-3.5 of this document, the Optical Pulse Generation (OPG) Subsystem is subject to the following specific requirements, controlled as a part of this SDR.

a. The range of injection energies from the OPG subsystem shall be from 0.1 to $10 \mathrm{Joules}$, in the required Haan pulse shape.

b. The OPG shall provide bandwidth as necessary to suppress Stimulated Brillouin Scattering, with failsafe

c. The OPG shall provide input pulses with spatially-shaped intensity profile to pre-correct for gain roll-off in the main amplifiers.

\subsubsection{Amplifier Subsystem Characteristics and Verification (WBS 1.3.2)}

In addition to requirements flowed down from Sections 3.2-3.5 of this document, the Amplifier Subsystem is subject to the following specific requirements, controlled as a part of this SDR.

a. The number of amplifier slabs in the cavity amplifier shall be 11 . The number of slabs in the booster amplifier shall be 7. (There is only one amplifier in the cavity, per 3.2.2.1)

b. The nominal amplifier slab thickness shall be $41 \pm 0.5 \mathrm{~mm}$

c. The flashlamp diameter shall be $43 \pm 1 \mathrm{~mm}$

d. The flashlamp explosion fraction shall be $\leq 20 \%$

e. The amplifier chain small-signal gain shall be $\geq 125,300$ from PAM to converter

\subsubsection{Pockels Cell System Characteristics and Verification (WBS 1.3.3)}

In addition to requirements flowed down from Sections 3.2-3.5 of this document, the Pockels Cell Subsystem is subject to the following specific requirements, controlled as a part of this SDR.

a. The overall optical transmission of the switch, including all losses such as absorption, reflection, and switching efficiency, shall be as follows:

switch on $->89.4 \%$

switch off $->90.3 \%$

b. The switching efficiency of the Pockels Cell, excluding static optical losses, shall be as follows:

switch on - >99\%

switch off $->99 \%$ 


\subsubsection{Amplifier Power Conditioning System Characteristics and Verification (WBS}

In addition to requirements flowed down from Sections 3.2-3.5 of this document, the Amplifier Power

Conditioning System is subject to the following specific requirements, controlled as a part of this SDR:

a. The total delivered energy shall be $\geq 294 \mathrm{MJ}$.

b. The flashlamp main pulse shape shall be a critically damped, single mesh pulse.

\subsubsection{Laser Auxiliary Systems Characteristics and Verification (WBS 1.3.5)}

In addition to requirements flowed down from Sections 3.2-3.5 of this document, the Laser Auxiliary Systems is subject to the following specific requirements, controlled as a part of this SDR.

The Laser Auxiliary Systems shall provide fluids, vacuum, cooling, electrical power, and other services as required by other Laser subsystems.

\subsubsection{Beam Transport Enclosures Characteristics and Verification (WBS 1.4.1)} All requirements for Laser System Spatial Filters/Enclosures are flowed down from other requirements in this document. The Beam Transport Enclosures shall meet all requirements in this SDR document.

\subsubsection{Interstage SubSystems Characteristics and Verification (WBS 1.4.2)}

All requirements for Laser System Interstage Systems are flowed down from other requirements in this document. The Interstage Systems shall meet all requirements in this SDR document.

\subsubsection{Support Structures Characteristics and Verification (WBS 1.4.3)}

All requirements for Laser System Support Structures are flowed down from other requirements in this document. The Support Structures shall meet all requirements in this SDR document.

\subsubsection{Optomechanical Systems Characteristics and Verification (WBS 1.4.4)}

All requirements for Laser System Optical Mounts are flowed down from other requirements in this document.

\subsubsection{Alignment Systems Characteristics and Verification (WBS 1.7.1)}

All requirements for Laser System Alignment Systems are flowed down from other requirements in this document.

\subsubsection{Beam Diagnostics Characteristics and Verification (WBS 1.7.2)}

All requirements for Laser System Beam Diagnostics are flowed down from other requirements in this document.

\subsubsection{Wavefront Control System Characteristics and Verification (WBS 1.7.3)}

In addition to requirements flowed down from Sections 3.2-3.5 of this document, the Wavefront Control

Subsystem is subject to the following specific requirements, which are controlled as a part of this SDR:

The actuators of the chain deformable mirror shall have an influence function of approximately $6 \mathrm{~cm}$.

The wavefront correction system shall be capable of operating closed-loop with a bandwidth of $\geq 1 \mathrm{~Hz}$. 


\subsubsection{Final Optics Characteristics and Verification Characteristics and Verification (WBS} 1.8.7) In addition to requirements flowed down from Sections 3.2-3.5 of this document, the Final Optics Subsystem is subject to the following specific requirements, controlled as a part of this SDR.

a. The converter configuration shall be Type 1/Type II; the design should not preclude future upgrade to an advanced converter design.

b. The final optics shall have a vacuum window on the $1 \omega$ laser side of the converter, to minimize likelihood of a catastrophic loss of vacuum.

c. The debris shields shall provide protection of the final optic assembly from target debris.

\subsection{QA Provisions}

Quality Assurance for this system will be determined by verification methods identified in Section 3, in combination with the identified Quality Level for individual components. 


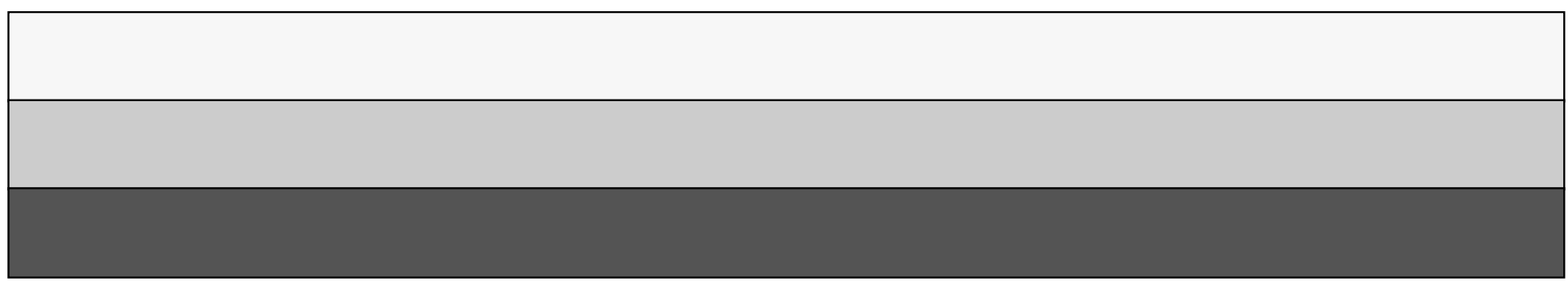

